\title{
Determinants Of Ethical Climate In The Firm: The Role Of Governance Control Systems And Environmental Uncertainty
}

John J. Williams, Singapore Management University, Singapore

Alfred E. Seaman, Humber College, Canada

\begin{abstract}
Corporate governance mechanisms essentially reside in the control structure/systems of most organizations and provide, theoretically at least, a conduit to support a better organizational ethical climate. This linkage, however, has seldom been portrayed this way in the literature and, correspondingly, there are virtually no empirical studies to offer increased understanding, especially with respect to the professional accountant in practice. Accordingly, this paper empirically assesses the governance mechanisms sanctioned by the International Federation of Accountants (2009) as determinants of an organization's ethical climate based on evidence from a Canadian sample of $\mathrm{CFOS/controllers.} \mathrm{The} \mathrm{ethics/leadership} \mathrm{literature} \mathrm{relating} \mathrm{to} \mathrm{ethical} \mathrm{climate}$ provides the theoretical underpinnings while organizational contingency theory supports examining the moderating effects of perceived environmental uncertainty (PEU). Increases in corporate governance control mechanisms are found to positively influence ethical climate. A significant relationship persists under both low and high levels of PEU but, as expected, it is much stronger when the level of PEU is low - which raises concerns about how to embrace a stronger ethical climate when uncertainty is high. This paper contributes to the governance and ethics literature by providing empirical evidence that normative directives on evaluating and improving governance in organizations from global accounting authorities, such as the IFAC, are effective in shaping firms' ethical climates in practice.
\end{abstract}

Keywords: Governance, Control Systems, Ethical Climate, Environmental Uncertainty

\section{INTRODUCTION}

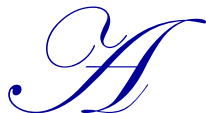

ccording to the International Federation of Accountants (IFAC, 2006b, p. ii), ethical conduct is a harbinger of successful business: "We do business with those we trust; we get business from those who trust us. ... Ethics, therefore, is a driver of business growth ..." There is virtual unanimity, though, that this cornerstone of business excellence has been repeatedly challenged by high profile business failures (Ponemon, 1995; Leung and Cooper, 2005), scandals of epic proportions (Waddock, 2005; Young and Annisette, 2009), perceptions of severe market competition (Jackson, Wood and Zboja, 2013), and, not least, trenchant globalization. In turn, concerns have spawned over the moral education of practicing accountants (Ponemon, 1990; Gaa, 1995; Sennetti, Shawver and Bancroft, 2004) and students (Clikeman and Henning, 2000; Bampton and Maclagan, 2005; Loeb, 2007), ethical behavior in the decision-making processes of individuals (Williams, 2002; Greer and Tonge, 2006), adequacy of professional codes of conduct (Brown, Stocks and Wilder, 2007), and the quality of the ethical climate within business organizations (Dickson, Smith, Grojean and Ehrhart, 2001). Accounting ethics research, although limited relative to the business ethics output (Uysal, 2010), has investigated the first three categories in some detail, but Brampton and Cowton (2013, p. 555) submit that the empirical findings and the proposed theoretical frameworks for expansion "have not been encouraging."

The business ethics literature also recognizes the importance of education, ethical training, and the development of a formal corporate code of ethics (Loe, Ferrell and Mansfield, 2000; Kaptein and Schwartz, 2008) as 
change agents impacting ethical behavior. However, Cullen, Victor and Stephens (1989, p. 61) recognized early on that "... changes in monitoring and supervision; and alterations in company policies, procedures, manuals, performance objectives, selection processes, and incentive structures" are of foremost importance in strengthening the ethical climate - precisely the types of governance systems advocated by the IFAC (2009). ${ }^{1}$ Strangely enough, the relationship between an institutional corporate governance code (grounded on "best practices" and directed at the accountant in business) and ethical climate at the firm level has not been examined empirically. As Pimentel, Kuntz and Elenkov (2008, p. 366) recommended, “... the identification of variables that foster strong ethical climates ... offers a promising avenue for researchers and practitioners."

This exploratory study examines determinants of an organization's ethical climate based on perceptions of Canadian CFOs pertaining to their organizations' governance structures. Specifically, the conformance and performance dimensions put forward by the International Federation of Accountants (2009) are used to measure six governance variables that, when enacted internally by an organization, should theoretically enhance its ethical climate. Given the legendary status of environmental uncertainty in structural contingency theory (Lawrence and Lorsch, 1967) and the suggested negative influences of uncertainty on ethical behavior (Triveno, 1986; Robertson and Anderson, 1993; Jackson et al., 2013), the model developed here is enriched by focusing on the moderating effects of PEU (Khandwalla, 1972; Miles and Snow, 1978; Tymon, Stout and Shaw, 1998).

The next section of this paper reviews the relevant literature and develops the corresponding hypotheses. This is followed by two sections describing the method and the research findings, respectively. In the final section, the implications of the study are discussed, several limitations are noted, and potential areas for further research are mentioned.

\section{PRIOR LITERATURE AND THEORETICAL DEVELOPMENT}

A review of the ethics literature which, by any standard, is vast and complex, manifests three major paradigms related to managing ethical behavior in the organization and corporate social responsibility: institutional, individual-based and value-based (Pimentel et al., 2008). Institutional approaches are based on compliance to existing codes of conduct, such as ethical codes governing the practice of professional accountants, while the second approach assumes that education can mold individuals to think and behave rationally in terms of their moral reasoning. Of more recent lineage is the view that ethical behavior is context-dependent and dominated, therefore, by an organization's ethical climate (Jones, Felps and Bigley, 2007) based on values espoused by its leadership (Dickson, et al., 2001). The modus operandi of this latter approach, called value-based ethics (Pimentel et al., 2008), is to align the values of the organization and its constituents through the dominant leader such that everyone shares the same perceptions about ethical behavior and standards. Processes that converge on these characteristics form the essence of an organization's ethical climate. One underdeveloped notion in the business ethics research literature is that proper corporate governance structures can provide the control systems necessary for positively servicing an organization's ethical climate.

Accounting ethics researchers, on their part, have expended considerable effort at the micro level studying various ethical aspects of professionals in practice, auditors, and students (Gaa and Thorne, 2004; Greer and Tonge, 2006; Satava, Caldwell and Richards, 2006). Apart from education curriculums, references to "best practices" or professional codes of conduct have been instrumental in this respect. In fact, Everett, Green and Neu (2005, p. 419) state that "The source of ethics most commonly referred to within accountancy is the formal ethical codes governing the profession." Less apparent and virtually invisible, given the absence of any accounting research, is the importance of organizational climate regarding ethics and the role of corporate governance for professional accountants in practice recently advocated, for instance, by the IFAC's 2009 International Good Practice Guidance: Evaluating and Improving Governance in Organizations. For some reason, though, linkages between the dual governance dimensions (i.e., conformance and performance) advocated by the IFAC (2009) and an organization's ethical climate remain unarticulated in the literature.

The argument put forth in this paper is that operational and strategic control systems (Tessier and Otley, 2012) are instrumental in shaping an organization's ethical climate through the responsible leadership of the CFO. Specifically, it is the system's underpinning the conformance and performance dimensions promulgated by the 
IFAC (2009) that are thought to be pivotal for enriching a firm's ethical climate, and it is the initiatives, directives and oversight mostly of the CFO that enable these two structural dimensions to unfold in the firm. This section, therefore, is in three parts. The first part briefly discusses the role of corporate governance mechanisms and codes of conduct, or best practice, from an institutional perspective; the second part discusses the linkage of ethical climate and corporate governance mechanisms; and the third part addresses the important moderating role of environmental uncertainty given its assumed impact on an organization's ethical climate.

\section{Control Mechanisms Embedded in Corporate Governance}

With the burgeoning global business scandals over the past several decades, international accounting institutions have responded in several ways to influence the professional conduct of accountants in practice and, perhaps more indirectly, the organization's ethical climate. In 2003, for instance, the IFAC issued a research document entitled Rebuilding Public Confidence in Financial Reporting - An International Perspective. Not surprisingly, recommendations based on organizational weaknesses called for more effective corporate ethics codes in addition to the provision of training and support for individuals within organizations. Subsequently, the IFAC/CIMA (2004) commissioned a research project to solicit the perceptions of professional accounting bodies on "ethical issues facing the profession, the causes of ethical failure and the role of ethics education" (Jackling et al., 2007, p. 929). The findings revealed overwhelming support for more ethics education via accounting curriculums and continuing professional development, prompting the conclusion that to improve the ethical climate in organizations “... the professional bodies are best placed...” (Jackling et al., 2007, p. 941).

The singular focus on education, however, fails to acknowledge control systems embedded in corporate governance structures as important antecedents of an organization's ethical climate - a position supported by the theoretical ethics literature as well as by pronouncements from accounting institutions with a global reach, such as the IFAC. In a study integrating individual ethics and ethical climate, Elango, Paul, Kundu and Paudel (2010, p. 543) opined that "The findings call for creating governance mechanisms to enhance ethical congruence, thereby increasing the likelihood of managers making ethical choices ..." Moreover, the IFAC issued a "best practices" guideline - Evaluating and Improving Governance in Organizations - to the international accounting community in 2009. In spirit, this guideline was directed at an organization's governing body; however, the professional accountant in practice was specifically implicated throughout because "... activities, in which the professional accountant in business is engaged, are strongly aligned with the activities included in the definition of governance ..." (IFAC, 2009, p. 6). These activities are manifested in ex ante and ex post control systems, performance measurement systems under generally accepted accounting principles, systems for managing internal control and risk, and systems aimed at drivers of value - all of which constitute structural phenomena in organization theory (Tymon et al., 1998). Moreover, the inextricable linkage between ethics and governance is clearly articulated by the IFAC (2009, p. 6): "IFAC's (2006a) Code of Ethics for Professional Accountants ... underpins the role of professional accountants in business in evaluating and improving governance in organizations ..." Unfortunately, this conveyance does not specify how governance structures can enhance ethics in an organization, nor does it offer any empirical evidence.

However, the IFAC's (2006a) ethics code for professional accountants specifies more succinctly how governance mechanisms and ethics are intertwined. The central idea is framed in terms of safeguards created by the profession, or regulations if legislated, which span the following areas: educational training for entry, continuing professional development, corporate governance regulations, professional standards, and professional or regulatory monitoring and disciplinary procedures (par. 100.12). However, safeguards can also emanate in the work environment in the form of lynchpin structures and control routines involving the following systems: the organization's corporate oversight structure, utilizing the organization's ethic's and conduct programs, strong internal controls, leadership that stresses the importance of ethical behavior, control systems to monitor the quality of performance, timely communication of the organization's governance system to all stakeholders, and quality feedback systems on unethical behavior (par. 300.16). Clearly, ethical climate is implicated in these safeguards and it would not emerge, grow, or mature in the firm without the presence of a central control system managed by the CFO (Henman, 2013).

Further support for the linkage of governance structures and ethical climate can be found in the November 
2006 exposure draft of the IFAC's Proposed Good Practice Guidance: Defining and Developing an Effective Code of Conduct. In the introduction, the draft (2006b, p. iii) states, "The PAIB Committee ... published a document in 2004 entitled Enterprise Governance - Getting the Balance Right. The document emphasized that Enterprise Governance includes two dimensions - conformance with rules and organizational performance. Underpinning these is the need to adhere to high standards of ethical conduct." The draft continues (2006b, par. 1.10) "As ... a CFO, an accountant may be directly involved ... by taking a leadership role ... and establishing the structures and approach required to execute an ethics, compliance, and values program." Moreover, codes of conduct and governance mechanisms "... play a vital role in strengthening the control environment, within which professional accountants can feature significantly by monitoring, reviewing, and reporting on performance" (IFAC, 2006b, par. 1.13). For these reasons, the conformance and performance dimensions of corporate governance served as the conceptual anchor in the present study for empirically measuring the independent variables that influence an organization's ethical climate.

\section{Ethical Climate in Organizations}

There is general agreement in the ethics literature that ethical climate is a component of organizational culture and, therefore, using the two concepts interchangeably can be confusing because they have different ontological origins. So, when embarking on any discussion of ethics, the initial tendency is to consider only individuals and avoid reifying entities such as corporations; but as Jackson et al., (2013, p. 233) point out, “... individuals do not operate in a vacuum. The organizational culture and context serve to shape or at least influence the ethical decision-making process of the individual." It is well-accepted that organizational culture shapes the organization's ethical climate in the form of corporate values (Ferrell, Gresham and Fraedrich, 1989; Hunt, Wood and Chonko, 1989), provides a social context (Trevino, 1986), and establishes an ethical framework (Mascarenhas, 1995).

However, the present focus is not on the larger concept of organizational culture but, rather, it is on context - the determinants of an organization's ethical climate from a control system (i.e., governance) perspective. Prior research by Sinclair (1993) and Wimbush, Shepard and Markham (1997) acknowledge that one prime factor that influences ethical behavior of employees is the ethical climate of the organization. The importance of ethical climate is also promoted by Jackson et al. (2013, p. 241) who cite Andreoli and Lefkowitz (2009): “... an organization's ethical climate is as critical in shaping behavior of those in a corporation as is a corporate code of ethics." The fundamental point is that organizational design features (Robertson and Anderson, 1993), which include all financial and non-financial control systems that fall under the rubric of corporate governance, may well affect ethical climate and, ultimately, the ethical behavior of a firm's members.

Victor and Cullen $(1987 ; 1988)$ are responsible for initially developing a two-dimensional model of ethical climates, with one dimension comprised of three ethical criteria derived from systems of "egoism", "benevolence", and "abstract principle" based on the work of Kohlberg (1984), Fritzche and Becker (1984) and Williams (1985). The second dimension, locus of analysis, builds on the sociology literature (Gouldner, 1957; Merton, 1957) which argues that ethical systems "may be applied to individuals, the organization, or society at large" (Cullen, et al., 1989, p. 54). Viewed as emergent control systems, ethical climates are "...multidetermined by societal norms", or the environment in which the organization functions; "organizational form", such as centralization or decentralization; and "firm-specific factors", most notably a firm's history (Victor and Cullen, 1988, p. 119).

Perhaps their most crucial empirical finding about ethical climate is that “... organizations did not have single climate types" (Victor and Cullen, 1988, p. 105), thus signifying that ethical climate is a multidimensional construct. Even so, they defined ethical climate as "... the shared perception of what is ethically correct behavior and how ethical issues should be handled ..." (Victor and Cullen, 1987, pp. 51-52). Dickson et al. (2001, p. 204) suggest that this definition is widely accepted in the ethics literature and remind us that it "is not focused on "what is right or wrong' but rather focuses on the things that organization members perceive the organization to see as ethical." In substance, this parallels Schneider's (1975) definition which stresses the paramount role of perceptions by members inside the organization, and not the views of external constituents. In terms of every day functioning, ethical climate relates to the way accountability, responsibility, regulations, communication, equity, trust, and the welfare of stakeholders are handled - and it is control systems and related routines that substantiate this domain. 
Several scholars have revisited the Victor and Cullen (1988) framework to describe antecedents of climate regarding ethics that include social norms, organization form, and firm-specific factors (Dickson et al., 2001; Grojean, Resick, Dickson, and Smith, 2004), with the conclusion that the only significant empirical research revolves around firm-specific factors - in particular, organizational leadership. Dickson et al. (2001, p. 208) argue that "the critical determinant of the climate regarding ethics is leader behavior" [italics in original]. They believe that establishing a strong ethical climate is the best way to capture the desired behavior of organizational members. This transpires when " leaders explicitly attend to their own values, determine the values that they wish to instill in organizational members, and make strategic organizational decisions that will facilitate the development of shared perceptions of appropriate ethical behavior" (Dickson et al., 2001, p. 198). These unfold through several mechanisms, including the role model image, enacting reward and punishment systems for specific types of behavior (Trevino, 1986), and adopting particular policies, structures, and operating systems. All these factors become implicated when the action repertoire of corporate governance mechanisms put forth by the IFAC (2009), for instance, are enacted by the firm's CFO, if not the CEO.

In elaborating on how this works, Dickson et al. (2001, p. 209) maintain that members' perceptions of these efforts "... come to be adopted as personal values, and to develop a moral imperative." From a similar perspective, Grojean et al. (2004) refer to Schein's (1992) analysis of primary and secondary mechanisms which embed the values of the leader in the culture of an organization. Primary embedding mechanisms used by the leader to communicate core values include "... rewards, resources allocation and gaining organizational status which result in an organization's climate" (Grojean et al., 2004 p. 225). Secondary mechanisms that embed organizational values include organizational design, routines, structures and mission statements - all of which are underpinned by the conformance and performance dimensions of corporate governance advocated by the IFAC (2009).

An assumption in the present paper is that CFOs are an integral part of strategic leadership along with CEOs (Boal and Hooijberg, 2000) and are instrumental in the design of control systems. Grojean et al. (2004, p. 233) nicely summarize literature specifying how this plays out: "Strategic leaders focus on broad policies and objectives (Barnard, 1938), planning and controlling (Page and Tornow, 1987) and provide a strategic vision that unifies the organization and provides a plan for the future (Smidt, 1998)." This unification is all about ethical climate and it entails the establishment of structures, processes, and control systems that are both forward-looking and historically-oriented (Zaccaro, 1996; House and Aditya, 1997; Ireland and Hitt, 1999), which precisely parallel the performance and conformance dimensions of corporate governance specified by the IFAC (2009).

Although the brief conceptual overview presented above suggests a direct relationship between an organization's ethical climate and the integrity of its formal control mechanisms, such a linkage does not appear to have been examined empirically in the business ethics literature, and certainly not with respect to the directives found in the IFAC (2009) pronouncement on best practices. Systematic reviews in the field of accounting ethics (Bernardi, 2005; Bernardi and Bean, 2007; Uysal, 2010; Bampton and Cowton, 2013) portray the same absence. Moreover, Bampton and Cowton (2013, p. 555) submit that "Regulatory developments and other initiatives, both domestically and internationally, offer some prospect ..." of improving ethical behavior but the "... most effective way forward would be for accountants to develop the ability to think and behave ethically, without having recourse to detailed regulations and standards." Unfortunately, this view misses the critical role served by prescribed codes of best practice, for example, and the potential benefits to the organization of an improved ethical climate, as promulgated in the ethics literature. Primentel et al. (2008, p. 366) put the matter eloquently: “... organizational accountability for business decisions is ensured internally through the implementation of knowledge structures and administrative systems that reinforce ethical behavior ... and responsible leadership that ensures clear communication ...." This is the recipe for a good ethical climate.

To recap, the IFAC has generated several international documents involving best practice guidelines that present an efficacious case for (1) the existence of a balanced repertoire of governance routines dealing with conformance and performance systems within the firm and (2) the necessary presence and improvement of these control systems to amplify an organization's cultural values and ethical climate as part of good corporate governance. Following arguments and discussion in the ethics literature, control systems of the type advocated by the IFAC seem to be central, if not indispensable, to enhancing ethical climate. Given the intersection of both of these literatures, the following research hypothesis is tested: 
H1: Higher levels of conformance and performance mechanisms in the firm positively influence ethical climate.

\section{The Role of Environmental Uncertainty}

Literature addressing the impact of an organization's external environment on its ethical climate is scarce. Dickson et al. (2001) address the issue of climate internalization in stable versus unstable environments. They suggest that certainty brings about ethical behavior since expectations are known and followed without any deviation, whereas conditions of instability or unpredictability create more variance in ethical behavior due to a lack of precedence or the sheer novelty of the situation. However, uncertainty can also be manifested in the form of competitive economic factors (Rajeev, 2012) that influence ethical behavior in the firm. For instance, price competitiveness and product quality can alter expectations and pressure firms to respond in unethical ways, mostly due to longer term uncertainties. Shleifer (2004) developed five examples of market competition, ranging from employment of children to corporate earnings manipulation, to illustrate the consequences of these economic factors on unethical behavior. In a study of sales forces, Robertson and Anderson (1993) drew similar conclusions in that a more competitive environment was associated with more unethical behavior. The notion of external networks anchored to suppliers and distributors indirectly points to another potential source of environmental uncertainty (Jackson et al., 2013), not simply due to the corresponding ethical values of the parties involved (Minett, 2002) but because hostile competitors encourage unethical decisions about the allocation of costs and benefits.

Based on the above arguments and cogent evidence, there is ample reason to consider how environmental uncertainty might affect the corporate governance/ethical climate relationship. The PEU construct developed in the accounting literature by Tymon et al. (1998) serves this purpose well and provides the strategic linkage between environmental uncertainty and the governance/ethical climate relationship that is called for in the contingency fit literature (Tushman and Nadler, 1978; Drazin and Van de Ven, 1985; Gresov, Drazin and Van de Ven, 1989). The model posits that top management perceptions of the external environment impact the organization's strategic decisions which, in turn, affect design decisions encompassing organizational structure and control systems. Tymon et al. (1998) identify four elements that characterize the role of PEU as a strategic construct: the external environment is the source of uncertainty, lack of knowledge about the interaction between external and internal processes means the external environment is shrouded in uncertainty, it is the de facto perceptions of these external elements that influence strategic decision-making in the context of altering the organization's control system structure, and the relevant perceptions about the environmental uncertainty facing the firm emanate from top managers, such as CEOs and CFOs, thus fixing the strategic orientation at the pinnacle of the organization.

However, there are concerns in the literature about how the PEU construct should be operationalized. Much of the accounting research literature views it as a unidimensional construct (Sharma, 2002) whereas organizational theory researchers recognize PEU as a multi-dimensional construct (Milliken, 1987; Gerloff, Muir and Bodensteiner, 1991; Sharfman and Dean, 1991). Studies that adopted Duncan's (1972) measure have been criticized because of confounding internal and external environmental referents in the scale. To avoid this concern, Tymon et al. (1998) recommend utilizing either of the scales developed by Khandwalla (1972) or Miles and Snow (1978) which incorporate only external environmental referents. Khandwalla's (1972) measure requires responses on the intensity of competition pertaining to five external referents (i.e., the competitiveness of prices, promotion, distribution, product quality, and product variety) which are deemed to be essential to the correct operationalization of the PEU construct. Several empirical studies have successfully used this PEU construct to examine management controls (Khandwalla, 1972), information system characteristics (Gordon and Narayanan, 1984), and managerial performance (Gul, 1991; Gul and Chia, 1994) at the organization level. Given the stance in the ethics literature on the presumed negative impact of uncertainty, higher levels of PEU should provide a weaker link between corporate governance mechanisms and ethical climate. Therefore, the second hypothesis tested is:

H2: When PEU is low, the relationship specified in Hypothesis H1 is significantly stronger than when PEU is high. 


\section{RESEARCH DESIGN}

\section{Data Collection and Sample}

Data were obtained from a survey questionnaire directed at CFOs/controllers of Canadian companies. These top-level managers were randomly chosen from the membership directory of the Society of Management Accountants of Canada. The survey instrument was web-based and part of a larger, ongoing research project involving Canadian-based companies. All companies retained in the sample had more than 200 employees, and this filter provided some degree of control over the size of firms in the sample. Respondents were cross-referenced to the Society's Registry to confirm active membership and designation. This boundary condition ensured that participants in the study had been exposed to the ethical knowledge and codes of professional conduct endorsed by the Society. These executives were targeted because of their overall knowledge of their firms' control systems, their interactive role in developing and implementing various governance mechanisms, and the assumed role of ethical leadership within their respective firms. The entire questionnaire was pilot-tested successfully to assess its length, understandability, and general attractiveness, as well as to ensure that minimum levels of reliability and validity could be attached to all measurement scales.

In total, 563 responses were received, but they were subjected to several filters. As mentioned above, firms with less than 200 employees were eliminated since their governance structures may not reflect those of larger companies nor manifest the same dynamic of leadership and organizational ethical climate. ${ }^{2}$ This reduced the eligible firms to 374. In addition, a tenure requirement of four years was invoked so as to ensure some degree of experience, expertise and responsibility in the role of leading the accounting function in the firm. Finally, utility and non-profit organizations were excluded for reasons of non-homogeneity following other management accounting research studies (e.g. Chenhall and Brownell, 1988; Brownell and Dunk, 1991). These two filters reduced the sample to 154 usable responses, of which 24 were incomplete and six indicated no variance. Removing these responses left a usable sample of 124 firms. Response bias was assessed following the procedures recommended by Armstrong and Overton (1977). The sample initially was split into two groups of approximately equal size based on the response date. The means and standard deviations of the measured variables were then compared for significant differences in the two sub-samples. This procedure manifested no evidence of response bias.

\section{Measures}

\section{Independent Variables}

The performance and conformance measures of corporate governance originally developed by Williams and Seaman (2010) were utilized in determining the independent variables for this study. Each dimension was measured by three scales that virtually map the corresponding guidelines overarching both dimensions that were identified by the IFAC (2009). The three scales in the conformance dimension covered accountability in the reporting function, providing assurances of ethical conduct and managing conflicts of interest, and assessments of the effectiveness of risk oversight. The purpose of using these three scales was to reflect the more historic or 'backward-looking' aspects of the ex post control systems subsumed in an organization's corporate governance structure. A more forward-looking set of scales in the performance dimension captured the ex-ante features incorporated in an organization's corporate governance structure. These were intended to reflect the accountant's role in the control processes dealing with strategy implementation and evaluation, external and internal communication processes, and value creation as specified by the IFAC (2009). Items for all six scales were rated on a fully anchored Likert scale ranging from 1 (to a very little extent) to 5 (to a very great extent). An average score was then calculated for each scale to represent the independent variable under investigation.

Turning to the conformance dimension first, the variable "accountability" (C1) was developed from a threeitem scale which yielded a single factor (eigenvalue of 2.52) that explained 80 percent of the total variance. Similarly, the two variables - "assurance" (C2) and "risk" (C3) - emerged as single factors from factor analyses (eigenvalues of 1.96 and 1.90) of two-item scales that explained 95 percent and 92 percent of the total variance, respectively. In addition, Cronbach's (1951) alpha statistic was calculated for each of the three scales yielding reliability coefficients of $0.81,0.94$, and 0.91 , respectively. Focusing on the performance dimension, the variable 
"strategy" (P1) was formed from a three-item scale that yielded a single factor (eigenvalue of 2.58) and explained 85 percent of the total variance. The "communication" (P2) variable was likewise generated by a three-item scale that yielded one factor (eigenvalue of 2.21) accounting for 76 percent of the total variance. The variable "value creation" (P3) was also formed by a three-item scale which produced one factor (eigenvalue of 2.14) explaining 72 percent of the total variance. Finally, calculated reliability coefficients based on Cronbach's alpha statistic were $0.92,0.81$, and 0.80 , respectively.

For each of the six independent variables, the emergence of eigenvalues greater than unity confirmed the single factor structure of each scale. Although more variance is explained in the set of compliance scales versus the performance scales, the calculated eigenvalues support the convergent validity in each set of scales. Moreover, the alpha coefficients range from 0.80 to 0.94 overall, with little difference between the conformance and performance variables. In fact, these coefficients are very strong for purposes of regression analysis and they more than satisfy Nunnally's (1967) inter-item reliability standard for exploratory behavioral research.

\section{Dependent Variable}

Measuring an organization's ethical climate is somewhat problematic and, arguably, rests on the nature of the research questions that are being addressed. Cullen et al. (1989) acknowledge that ethical climate is simply one component of organizational culture and, moreover, make it clear that organizations do not have single types of ethical climate. They initially approached the problem of measuring ethical climate by constructing nine possible theoretical types based on a three-by-three matrix (Victor and Cullen, 1988). Following Kohlberg (1984), Victor and Cullen (1988) show three types of ethical criteria on the vertical axis: egoism, benevolence, and principle. The horizontal axis lists three levels of analysis: individual, local (group or organization), and cosmopolitan (society at large). Hence, theoretically, ethical climate may focus on any one or a combination of nine factors as shown in Table 1: "self-interest, company profit, efficiency, friendship, team interest, social responsibility, personal morality, rules and standard operating procedures, or laws and professional codes" (Cullen et al., 1989, p. 55).

Factor analysis to determine what factors actually exist in practice has produced equivocal results. For example, Victor and Cullen (1988) produced five factors, with three of them containing multiple combinations of the nine theoretical factors (see italics in Table 1). Wimbush and Shepard (1997), using a modified instrument, also produced five factors but one was different from Victor and Cullen's set while laws and rules were combined. Moreover, the ranking of the factors in terms of average scores was not isomorphic across these two studies and it was not possible to ascertain what percentage of the total variance was explained in the retained factors from the factor analysis. The point here is that both studies were examining dimensions of ethical climate in different subunits at multiple levels of analysis, in different firms, and across different industries.

The objective in this paper was to create a composite measure of ethical climate that is representative of CFO perceptions at the firm level and not at the sub-unit, group, nor individual level per se. ${ }^{3}$ As Victor and Cullen (1988, p. 119) advised, “... the climates ... for groups within organizations are defined primarily in terms of the fundamental ethical criteria described. Only within the principle criterion, however, did the loci of analysis define different climate types. This suggests that, unlike climates emphasizing egoism or benevolence criteria for decisionmaking, ethical climates based on the use of principles or rules have an organization-relative focus generated by the individual, the organization, or by other systems such as the law" (emphasis added). Thus, the ethical criterion of egoism was eliminated from this study, leaving the shaded cells in Table 1 as the primary focus. With this qualification in mind, and with the explicit exclusion in this study of an individual or group focus, ethical climate was measured using 16 items adapted from the instruments used by Victor and Cullen (1988) and Schminke, Ambrose and Neubaum (2005). Factor analysis using a principal components procedure with Varimax rotation yielded three usable scales. All items were rated on a fully anchored Likert scale ranging from 1 (to a very little extent) to 5 (to a very great extent). 
Table 1: Victor And Cullen's Ethical Climate Matrix $(1987,1988)$

\begin{tabular}{|c|c|c|c|c|}
\hline & \multicolumn{3}{|c|}{ LOCUS OF ANALYSIS } \\
\hline & & Individual & Local & Cosmopolitan \\
\hline \multirow{3}{*}{ 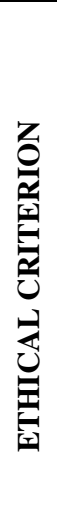 } & 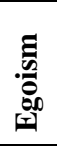 & $\begin{array}{l}\text { Self-interest } \\
\text { Instrumental }\end{array}$ & $\begin{array}{l}\text { Company Profit } \\
\text { Instrumental }\end{array}$ & $\begin{array}{l}\text { Efficiency } \\
\text { Caring }\end{array}$ \\
\hline & $\begin{array}{l}\stackrel{0}{0} \\
\frac{0}{0} \\
0 \\
0 \\
0\end{array}$ & $\begin{array}{l}\text { Friendship } \\
\text { Caring }\end{array}$ & $\begin{array}{l}\text { Team Interest } \\
\text { Caring }\end{array}$ & $\begin{array}{l}\text { Social Responsibility } \\
\text { Caring }\end{array}$ \\
\hline & 尝 & $\begin{array}{l}\text { Personal Morality } \\
\text { Independence }\end{array}$ & $\begin{array}{l}\text { Company Rules and Procedures } \\
\text { Rules }\end{array}$ & $\begin{array}{l}\text { Laws and Professional Codes } \\
\text { Law and Code }\end{array}$ \\
\hline
\end{tabular}

Adapted from Simha and Cullen (2011). Bold italics denote empirical dimensions. Shaded cells depict the focus of the present study.

The first scale, labeled "compliance and accountability", contained three items: (1) people value respect at all levels of the organization, (2) the organization ensures compliance with laws and regulations, and (3) the organization holds me accountable for my decisions. The single-factor structure of the scale was confirmed by factor analysis. One significant factor emerged with an eigenvalue of 2.39 , which explained 79.5 percent of the total variation. This factor simulates the combined "rules" and "law and code" factors empirically derived by Victor and Cullen (1987, 1988). The second scale, called "social accountability", also contained three items: (1) time is spent in this organization on ethics training, (2) the organization devotes sufficient resources to conducting a social audit, and (3) the organization spends time reporting the social audit to the public. Again, factor analysis yielded one significant factor with an eigenvalue of 2.42 , which explained 80.6 percent of the total variance. Notably, this factor strongly parallels the "caring" factor empirically derived by Victor and Cullen $(1987,1988)$. Finally, the third scale, designated "firm integrity", was comprised of three items: (1) people value honesty at all levels of the organization, (2) people value trustworthiness at all levels of the organization, and (3) top management models ethical behavior. One significant factor resulted from factor analysis with an eigenvalue of 2.17, which explained 72.2 percent of the total variance. This factor also closely matches the "caring" factor empirically derived by Victor and Cullen (1987, 1988). Cronbach alpha coefficients of $0.70,0.87$ and 0.85 , respectively, confirmed the reliability of the scales. Finally, an average score was calculated for each of the three scales which were then summed and averaged to generate the dependent variable for each firm in the regression model.

\section{Moderating Variable}

PEU was measured using an adapted version of the competitive pressure scale originally developed by Khandwalla (1972), which Tymon et al. (1998) asserted is the only one that clearly measures perceived uncertainty of the external environment. Respondents were asked for their assessment of the intensity of competition on a fully anchored Likert scale ranging from 1 (far below average intensity) to 5 (far above average intensity) pertaining to five dimensions in the external environment: raw materials, technical personnel, selling and distribution, quality and variety of products, and price. ${ }^{5}$ This scale was preferred over others because arguments from the literature on ethical climate noted earlier appear to single out competitive economic factors as potentially influencing an organization's ethical climate but failed to mention the effects of factors such as turbulence and technology. A simple average of the responses to these five items was used as the measure of PEU. For this study, the scale achieved a Cronbach alpha coefficient of 0.68 , only marginally acceptable by behavioral research standards. By comparison, Sharma (2002) obtained an alpha statistic of 0.57 for similar PEU items, Gul (1991) reported 0.77, and Gul and Chia (1994) achieved a value of 0.73. Given the broad-based nature of the sample obtained in the present study, encompassing a large geographic region, tapping multiple industries, and enveloping heterogeneous competitive factors, the reliability of the PEU measure for this study was deemed acceptable. Finally, the PEU scores for all firms were dichotomized at the mean of the distribution to create two categorical variables for testing 
the research hypothesis $\mathrm{H} 2 .^{6}$ A dummy variable was coded either zero or one for low PEU and high PEU, respectively.

\section{Analysis}

To investigate H1, which involves the impact of the conformance and performance dimensions of corporate governance on ethical climate, a multiple regression model of the following form was utilized:

$\mathrm{EC}=\alpha+\beta_{1} \mathrm{P} 1+\beta_{2} \mathrm{P} 2+\beta_{3} \mathrm{P} 3+\beta_{4} \mathrm{C} 1+\beta_{5} \mathrm{C} 2+\beta_{6} \mathrm{C} 3+\epsilon$

where $\mathrm{EC}=$ ethical climate, $\mathrm{P} 1=$ strategy, $\mathrm{P} 2=$ value creation, $\mathrm{P} 3=$ communication, $\mathrm{C} 1=$ accountability, $\mathrm{C} 2=$ assurance, and $\mathrm{C} 3=$ risk. A significant finding would supply evidence of main effects of the conformance and performance dimensions on ethical climate and thus, statistically, the research hypothesis $\mathrm{H} 1$ would be accepted. To test H2, Eq. (1) was re-run for both the low and high PEU sub-samples. A significant $\mathrm{R}^{2}$ difference between the two sub-samples would offer evidence for not rejecting hypothesis $\mathrm{H} 2$.

\section{RESULTS}

\section{Descriptive Statistics}

Table 2 presents the means, standard deviations, theoretical ranges, and actual ranges for all measured variables in the study while Table 3 reports the Pearson correlation matrix for the same set of variables. ${ }^{7}$ A review of the correlation values between the various independent variables shows some degree of statistical significance; however, more than one-half of them are weakly related $(<0.50)$ and none of them are strongly related $(>0.80)$. Williams and Seaman (2010) explained that these generally weak correlations overall are not unexpected because the independent variables are sub-dimensions of a larger single construct representing corporate governance. The behavioral literature (Perrow, 1970; Brownell, 1982; Daft, 1983) maintains that this phenomenon is not unusual in empirical social science research. Also, Table 3 reveals that the moderating variable, PEU, is virtually uncorrelated with the set of independent variables, with only one instance of a very weak relationship (P4). Finally, Table 3 indicates that PEU is correlated with the dependent variable, EC, which is an important property in regression analysis (Shields and Shields, 1998).

Table 2: Descriptive Statistics $(n=124)$

\begin{tabular}{lcccc}
\hline \multicolumn{1}{c}{ Variable } & Mean & $\begin{array}{c}\text { Standard } \\
\text { Deviation }\end{array}$ & Theoretical Range & Actual Range \\
\hline 1. EC & 3.587 & 0.636 & $1-5$ & $1-5$ \\
2. Strategy (P1) & 3.591 & 1.163 & $1-5$ & $1-5$ \\
3. Communication (P2) & 2.723 & 1.215 & $1-5$ & $1-5$ \\
4. Value creation (P3) & 3.643 & 0.986 & $1-5$ & $1-5$ \\
5. Accountability (C1) & 4.240 & 0.902 & $1-5$ & $1-5$ \\
6. Assurance (C2) & 2.934 & 1.386 & $1-5$ & $1-5$ \\
7. Risk (C3) & 3.230 & 1.309 & $1-5$ & $1-5$ \\
8. PEU & 3.254 & 0.416 & $1-5$ & \\
\hline V. &
\end{tabular}

Variable definitions: $\mathrm{EC}=$ ethical climate; $\mathrm{PEU}=$ perceived environmental uncertainty. 
Table 3: Pearson Correlation Matrix $(\mathrm{n}=124)$

\begin{tabular}{|c|c|c|c|c|c|c|c|}
\hline Variable & 1 & 2 & 3 & 4 & 5 & 6 & 7 \\
\hline 1. EC & & & & & & & \\
\hline 2. Strategy (P1) & $0.367 * *$ & & & & & & \\
\hline 3. Communication (P2) & $0.261 * *$ & $0.653 * *$ & & & & & \\
\hline 4. Value creation (P3) & $0.643 * *$ & $0.474 * *$ & $0.356 * *$ & & & & \\
\hline 5. Accountability $(\mathrm{C} 1)$ & 0.161 & $0.442 * *$ & $0.377 * *$ & $0.341 * *$ & & & \\
\hline 6. Assurance (C2) & $0.452 * *$ & $0.627 * *$ & $0.551 * *$ & $0.487 * *$ & $0.412 * *$ & & \\
\hline 7. Risk (C3) & $0.217 *$ & $0.693 * *$ & $0.593 * *$ & $0.391 * *$ & $0.541 * *$ & $0.599 * *$ & \\
\hline 8. PEU & $0.238 * *$ & 0.093 & 0.061 & $0.213^{*}$ & $(0.065)$ & 0.169 & 0.062 \\
\hline
\end{tabular}

Variable definitions: $\mathrm{EC}=$ ethical climate; $\mathrm{PEU}=$ perceived environmental uncertainty.

$*<0.05$.

$* *<0.01$.

\section{Regression Results}

Table 4 reports the results of the regression analyses. Hypothesis $\mathrm{H} 1$ contends that the independent governance variables, from both the performance and conformance dimensions, will have a positive effect on the organization's ethical climate. The results of Eq. (1) presented in column 2 confirm a significant relationship (adjusted $\mathrm{R}^{2}=0.380 ; \mathrm{F}=17.936 ; \mathrm{p}<0.010$ ) and, therefore, provide substantial support for hypothesis $\mathrm{H} 1{ }^{8}{ }^{8}$ For the performance dimension of governance, variables P1 and P3 are significantly and positively associated with the dependent variable, EC, while P1 is marginally negative and not statistically significant. Turning to the conformance dimension, variable $\mathrm{C} 2$ is significantly and positively associated with $\mathrm{EC}$ whereas the risk variable, C3, surprisingly, is significantly negative. Finally, the accountability variable, C1, is not associated with EC. Overall, the findings are largely in the direction anticipated.

Table 4: Regression Results

\begin{tabular}{|c|c|c|c|}
\hline Variable & Full Model & Low PEU & High PEU \\
\hline Strategy (P1) & $0.149^{*}$ & 0.131 & 0.098 \\
\hline Communication (P2) & $(0.025)$ & 0.011 & $(0.032)$ \\
\hline Value creation (P3) & $0.512 * * *$ & $0.539 * * *$ & $0.598 * * *$ \\
\hline Accountability (C1) & 0.047 & $(0.104)$ & $(0.042)$ \\
\hline Assurance (C2) & $0.232 * * *$ & $0.379 * * *$ & 0.144 \\
\hline Risk (C3) & $(0.250)^{* * *}$ & $(0.302)^{* *}$ & $(0.131)$ \\
\hline $\mathrm{N}$ & 124 & 71 & 53 \\
\hline $\mathrm{R}^{2}$ & 0.402 & 0.491 & 0.435 \\
\hline Adjusted $\mathrm{R}^{2}$ & 0.380 & 0.443 & 0.361 \\
\hline $\mathrm{F}$ & $17.936 * * *$ & $10.280 * * *$ & $5.897 * * *$ \\
\hline
\end{tabular}

Variable definitions: $\mathrm{PEU}=$ perceived environmental uncertainty.

$*<0.10$.

$* *<0.05$.

$* * *<0.01$

Hypothesis $\mathrm{H} 2$ states that the relationship between the corporate governance variables and ethical climate will be stronger under low levels of PEU as opposed to high levels. Eq. (1), therefore, was re-estimated for each of the two sub-samples and the results are reported in columns 3 and 4 of Table $4 .{ }^{9}$ When the level of PEU is low, there is a significant relationship between the corporate governance variables and ethical climate (adjusted $\mathrm{R}^{2}=$ $0.443 ; \mathrm{F}=10.280 ; \mathrm{p}<0.010)$. As predicted, though, a significant, but weaker, relationship emerges when the level of PEU is high (adjusted $\mathrm{R}^{2}=0.361 ; \mathrm{F}=5.897 ; \mathrm{p}<0.010$ ). To provide a direct test of hypothesis $\mathrm{H} 2$, the regression results from columns 3 and 4 were compared using the Chow test (Chow, 1960) to test for structural differences. The result revealed that the two regression equations were significantly different $(F=6.117 ; p<0.010)$. This finding not only confirms the expected moderating effects of PEU differences on the corporate governance/ethical climate relationship, but it also provides strong evidence in support of hypothesis $\mathrm{H} 2$.

More specifically, the pattern of the independent variables is not consistent across the partial regression models when the two dimensions of corporate governance are contrasted. For the set of performance governance variables, there is virtually little change in the magnitude of the coefficients in the full regression model versus the 
low PEU sub-sample. Clearly, value creation (P3) is highly important in relation to ethical climate at all PEU levels. However, this pattern is not repeated for the conformance dimension of corporate governance. Here, assurance (C2) is only significantly positively associated with EC at low levels of PEU. Moreover, although risk (C3) is significantly negative in the full model, it only retains this quality at low levels of PEU. Finally, it appears that value creation (P3) is the single most important variable driving the corporate governance/ethical climate relationship under high PEU. Nonetheless, the findings collectively provide compelling evidence, based on the $\mathrm{R}^{2}$ values manifested in Table 4, that the corporate governance variables are important determinants of ethical climate and are influenced by the level of PEU.

\section{DISCUSSION AND IMPLICATIONS}

As acknowledged earlier, the nature of the relationship between corporate governance control mechanisms and ethical climate is elusive since there is no ready empirical evidence by which an assessment or comparison can be made, yet the literature acknowledges that an important aspect of corporate governance is creating and maintaining a positive ethical climate (Monks, 2002; IFAC, 2009; Elango et al., 2010). The objective of this study, therefore, was to explore possible determinants of ethical climate at the organization level with measures derived from the conformance and performance governance characteristics put forth by the IFAC (2009). Findings from the full regression model indicate a strong overall relationship supported by the adjusted $\mathrm{R}^{2}$ of $0.402(\mathrm{~F}=17.936 ; \mathrm{p}<$ 0.001 ) reported in Table 4 and the corresponding significant correlations reported in Table 3. The most important positive determinants of ethical climate are strategy (P1), value creation (P3), and assurance (C2) while risk (C3) operates inversely - meaning less risk enhances ethical climate. In addition, the communication variable (P2) and accountability variable $(\mathrm{C} 1)$ are not important predictors of ethical climate for this sample. Nonetheless, both dimensions of corporate governance feature important determinates of ethical climate which, for the full model at least, should alleviate concerns advanced in a report by the IFAC (2008) indicating that organizations direct a disproportionate amount of attention to compliance mechanisms at the expense of performance mechanisms.

What is perhaps most striking in these outcomes for the conformance dimension is that the accountability (C1), assurance (C2), and risk (C3) variables do not function at all uniformly in their impact on the firm's ethical climate. More specifically, accountability has no effect, assurance has a strong positive effect, and risk has a strong negative effect on ethical climate. One possible explanation of the insignificant finding for accountability is that it reflects the prescriptive nature of strict adherence to an institutionalized professional code of conduct, standardized reporting requirements, and legal compliance with generally accepted accounting principles - routines that do not enhance perceptions of what is perceived to be correct behavior within the firm. This interpretation is consistent with definitions of ethical climate presented earlier and nicely phrased by Brief, Dukerich, Brown and Brett (1996, p. 193) who call it "the 'feel' of an organization ... the perceptions of organizational members about how organizations function and/or what is important in their organizations."

The emergence of a significant negative effect for risk on ethical climate may not be so surprising, retrospectively, and certainly supports the decision to examine the moderating effects of uncertainty in the organization's external environment. Generically, risk is a variance between some potential, uncertain, event and the present status and this gives rise to the notion of certainty (no variance) and uncertainty. There is ample literature to suggest that ethical behavior is compromised when the proper actions to take are unknown (Shein, 1992; Dickson et al. (2001). Williams and Seaman (2010, p. 10) made the point that “... practicing accountants at senior levels of the organization are probably involved with issues of risk, albeit indirectly rather than directly, thus limiting their ability to enlarge the network of risk processes and procedures." The findings in the present study support this reasoning, paradoxically, in that ethical climate is enhanced when less attention is devoted by the CFO to risk identification and the implementation of appropriate risk management systems. This is equivalent to endorsing less uncertainty as a means to enhancing the organization's ethical climate. Alternatively, it is possible that the risk measure adopted was simply too crude in the present study to discriminate between uncertainty in the firm's internal and external environments. Future research studies might consider incorporating Perrow's (1967) construct of technology (i.e., task difficulty and task variety) as a moderating variable to ascertain how the uncertainty associated with the firm's work transformation process might impact ethical climate.

Turning to the performance dimension of governance, both the strategy (P1) and value creation (P3) 
variables are significant determinants of ethical climate, with the latter being the most important. However, the regression analysis shows that communication (P2) is not a significant determinant of ethical climate. This outcome is curious since Falkenburg and Herremans (1995) make it understood that formalized policies of conduct and documented codes of ethics are elements of control systems that "clearly communicate the accepted and expected standards of ethical conduct ... and reduce ambiguity ..." (Grojean et al., 2004, p. 229). Quite possibly the communication variable in the performance dimension did not reflect these expectations because the referents appeared to focus more on rule compliance and discipline in the communication function. Moreover, communication among stakeholders, the Board, operating personnel and the general public was likely financial in nature and too aggregated to glean any sense of ethical underpinnings. Put differently, the measured communication variable in this study was possibly too broad and it simply could not capture any perceived benefits that would enhance ethical climate.

The significant relationship between the governance variables and ethical climate persists across both levels of PEU as reflected by the adjusted $\mathrm{R}^{2}$ of $0.443(\mathrm{~F}=10.280 ; \mathrm{p}<0.001)$ and $\mathrm{R}^{2}$ of $0.361(\mathrm{~F}=5.897 ; \mathrm{p}<0.001)$ reported in Table 4, respectively. Hypothesis $\mathrm{H} 2$ posits a significantly stronger relationship under the condition of low PEU versus high PEU. The Chow test F-statistic for testing structural change between the two regressions confirmed the significance of the 22.7 percent increase in adjusted $R^{2}$ (i.e., $(0.443-0.361) / 0.361$ ) for the low PEU sub-sample over the high PEU sub-sample, thus providing strong statistical support for H2. Two further salient features appear in Table 4. First, the rank order of the regression coefficients for the independent variables in terms of their magnitude is isomorphic across the reduced models for PEU (i.e., column 3 versus column 4), signaling the robustness of the independent governance variables and lending some theoretical support to their selection in the present model. Second, what does change dramatically, however, is the emergence of the value creation variable, $\mathrm{P} 3$, as the only significant variable in the high PEU sub-sample. With the marginal exception of the strategy variable, P1, the regression coefficients in the low PEU sub-sample are remarkably similar in importance (i.e., magnitude) as compared to the full sample. Given the prominent role of PEU observed in this study, it seems appropriate to explore its influence with refined measures on samples that control for location, industry, manufacturing versus service sectors, size, organization structure, and perhaps public versus private ownership, since the concept of environmental uncertainty is equivocal at best and possibly contingent on some or all of these factors.

In closing, the empirical results of this exploratory study reveal correlates of ethical climate that are congruent with the conformance and performance dimensions of corporate governance prescribed by the IFAC (2009). Equally important, results from the reduced models show that uncertainty in the external environment substantially weakens this relationship relative to conditions of more certainty. Given the salient role of PEU observed in this study, more empirical work is necessary to understand the types of control systems that could enhance ethical climate in turbulent and diverse environments, including, of course, appropriate refinements to the dependent and independent variables. Clearly, the generalizability of these results is indeterminate and calls for further studies with larger samples. Other limitations of this study are worth noting, including common-method bias from self-reported data (Kren, 1992) which could bias the model relationships, and the inability to ascertain nonresponse bias as a result of obtaining survey data from the Internet. The number of filters deployed to create the sample was very restrictive and produced a sample size that was not as large as desired. Furthermore, restricting the respondents to accounting-based positions in the firm assumed that they had requisite knowledge that was equal, or superior, to other functional managers or executives in the firm.

Future research studies can strive to circumvent these difficulties and perhaps examine other stakeholders as well, including divisions within the firm, cross-industry, or cross-cultural effects. These caveats notwithstanding, the findings challenge the view that " ... the professional bodies are best placed to promote ethical behavior in the workplace via membership and ongoing educational development of members" (Jackling, et al., 2007, p.940). It would seem that governance structures incorporating control systems that embrace an organization's ethical climate, patently endorsed by CFO leadership, also have a place in promoting ethical behavior. As Grojean et al. (2004, p. 225) frame it: “. . it is the organization's leaders that enact the goal, policies, and practices ... and thus play the primary role in the creation of climates related to ethics." 


\section{ENDNOTES}

1. The IFAC is used as the institutional referent by default in this study for two major reasons. First, its membership is truly global - with more than 163 member organizations in over 120 countries (Jackling, Cooper, Leung and Dellaportus, 2007, p. 941) - and, therefore, its high quality recommended practices for the world accountancy profession are the benchmark for excellence in governance structures. Second, it provides the conceptual foundation for the correlates of ethical climate developed in the present study.

2. Murphy, Smith and Daley (1992) present empirical evidence showing that operational factors in larger firms are positively associated with better ethical conduct while the reverse effect holds for smaller firms. Given the emphasis on governance mechanisms (i.e., control systems) in the present study, a decision was made to exclude smaller firms.

3. Other empirical studies have successfully adopted a unidimensional, or aggregate, measure of ethical climate at the firm level of analysis (see, for example, Schwepker, Ferrell, and Ingram (1997), Weeks (2004), Jaramillo, Mulki and Solomon, (2006), and Mulki, Jaramillo and Locander, (2008).

4. A supporting reason for omitting the egoism criterion is based on multiple empirical research studies which show that instrumental climates are negatively associated, not only with a variety of outcome variables, but also consistently with caring, independence, rules, and law and code climates (Deshpande, 1996; Elçi and Alpkan, 2006; Tsai and Huang, 2008; Goldman and Tabak, 2010; and Wang and Hsieh, 2012). Also, Joseph and Deshpande (1997) report that efficiency climates are similarly negative in the same manner. Therefore, egoism (as a self-interest referent) is not consonant with developing an aggregate ethical climate variable in the present study nor is it compatible with the intentions of the IFAC (2009) in enhancing an organization's ethical climate.

5. Initially, items representing environmental turbulence and technology were incorporated into the pilot study, but the responses indicated virtually no variance. Discussions with respondents in the pilot study questioned the relevance of these items to nurturing an ethical climate in the firm. Consequently, these items were discarded from further analysis.

6. A mean-split was utilized for parsimonious reasons in an effort to preserve as large a data set as possible, even though the two categories of low and high PEU were not equal in sample size. A median-split was rejected because of confounding effects in the two categories; that is, PEU responses with the same value in each category would nullify any conclusions of moderating effects on the relationship under study.

7. Parametric statistical tests are potentially problematic with survey data. Hence, a non-parametric Kolmogorov-Smirnov test was applied to both the dependent and independent variables to ascertain univariate normality. The $z$-statistics were not significant and, thus, the null hypothesis that the sample was drawn from a normal population could not be rejected at a significance level of $\mathrm{p}<0.10$.

8. To ensure the absence of multi-collinearity in the full regression model, a Variance Inflation Factor was calculated. The VIF was slightly above 1, well within acceptable limits.

9. Pearson correlation coefficients were calculated for each sub-sample and no significant differences were observed. In addition, each sub-sample was checked for univariate normality using the KolmogorovSmirnov $z$-statistic while the Mahalanobis multivariate test was applied to each regression. No abnormalities were found in either case.

\section{AUTHOR INFORMATION}

Dr. Williams has been a Professor of Accounting at the University of Alberta, Canada; University of Nairobi, Kenya; Queen's University, Canada; Nanyang Technological University, Singapore; and is currently a Practice Associate Professor in the School of Accountancy, Singapore Management University, Singapore. He has consulted internationally and conducted extensive research on management accounting control systems, with publications in Accounting, Organizations and Society, Behavioral Research in Accounting, California Management Review, Contemporary Accounting Research, Journal of Accounting Historians, Journal of Applied Business Research, Management Accounting Research, and Review of Business Information Systems. E-mail: jjwilliams@ @mu.edu.sg.

Dr. Seaman is a Professor of Accounting at The Business School, Humber Institute of Technology \& Advanced Learning. He has several years of professional experience providing accounting and consulting services to private and public organizations. His research has investigated organization strategy, structure and process as they relate to 
management accounting and control systems. Currently, Dr Seaman is conducting research in Canadian organizations with the focus being governance, ethics, and management accounting systems and their relationship to the set of cognitive high reliability characteristics. E-mail: alfred.seaman@ humber.ca (Corresponding author)

\section{REFERENCES}

1. Andreoli, N. and Lefkowitz, J. (2009), Individual and organizational antecedents of misconduct in organizations, Journal of Business Ethics, Vol. 85, pp. 309-332.

2. Armstrong, J. S. and Overton, T. S. (1997), Estimating nonresponse bias in mail surveys, Journal of Marketing Research, Vol. 14, pp, 396-402.

3. Bampton, R. and Cowton, C. J. (2013), Taking stock of accounting ethics scholarship: A review of the journal literature, Journal of Business Ethics, Vol. 117, pp. 549-563.

4. Bampton, R. and Maclagan, P. (2005), Why teach ethics to accounting students: A reply to the sceptics, Business Ethics: A European Review, Vol. 14, No. 3, pp. 290-300.

5. Barnard, C. I. (1938), The functions of the executive, Harvard University Press, Cambridge.

6. Bernardi, R. A. (2005), Accounting scholars publishing in business ethics journals: A thirty-year longitudinal study, Research on Professional Responsibility and Ethics in Accounting, Vol. 10, pp. 63-93.

7. Bernardi, R. A. and Bean, D. F. (2007), The growth of accounting research in ethics journals: A 45-year longitudinal study in Jeffery, C. (Ed.), Research on Professional Responsibility and Ethics in Accounting, Vol. 11, pp. 47-62.

8. Boal, K. B., and Hooijberg, R. (2000), Strategic leadership research: Moving on, Leadership Quarterly, Vol. 11, pp. 515-549.

9. Brief, A. P., Dukerich, J. M., Brown, P. R. and Brett, J. H. (1996), What's wrong with the Treadway Commission Report? Experimental analyses of the effects of personal values and codes of conduct on fraudulent financial reporting, Journal of Business Ethics, Vol. 15, pp. 183-198.

10. Brown, P. A., Stocks, M. H. and Wilder, W. M. (2007), Ethical exemplification and the AICPA code of professional conduct: An empirical investigation of auditor and public perceptions, Journal of Business Ethics, Vol. 71, pp. 39-71.

11. Brownell, P. (1982), The role of accounting data in performance evaluation, budgetary participation, organizational effectiveness, Journal of Accounting Research (Spring), pp. 12-27.

12. Brownell, P. and Dunk, A.S. (1991), Task uncertainty and its interaction with budgetary participation and budget emphasis: some methodological issues and empirical investigation, Accounting Organizations and Society, Vol. 16, No. 8, pp. 693-703.

13. Burns, T. and Stalker, G. M. (1961), The Management of Innovation, London, Tavistock.

14. Chenhall, R. and Brownell, P. (1988), The effect of participative budgeting on job satisfaction and performance: Role ambiguity as an intervening variable, Accounting, Organizations and Society, Vol.13, No. 3, pp. 225-234.

15. Chow, G. C. (1960), Tests on equality between sets of coefficients in two linear equations, Econometrica, Vol. 28, pp. 591-605.

16. Clikeman, P. M. and Henning, S. L. (2000), The socialization of undergraduate accounting students, Issues in Accounting Education, Vol. 15, No. 1, pp. 1-17.

17. Cronbach, L. J. (1951), Coefficient alpha and the internal structure of tests, Psychometrika, Vol. 16, pp. 297-334.

18. Cullen, J. B., Victor, B. and Stephens, C. (1989), An ethical weather report: Assessing the organization's ethical climate, Organizational Dynamics, Vol. 18, No. 2, pp. 50-63.

19. Daft, R. L. (1983), Organizational theory and design, West Publishing, St. Paul, MN.

20. Deshpande, S. P. (1996), Ethical climate and the link between success and ethical behavior: An empirical investigation of a non-profit organization, Journal of Business Ethics, Vol. 15, pp. 315-320.

21. Dickson, M. W., Smith, D. B., Grojean, M. W. and Ehrhart, M. (2001), An organizational climate regarding ethics: The outcome of leader values and the practices that reflect them, The Leadership Quarterly, Vol. 12, No. 2, pp. 197-217.

22. Drazin, R. and Van de Ven, A. H. (1985), Alternative forms of fit in contingency theory, Administrative Science Quarterly, Vol. 30, pp. 514-39.

23. Duncan, R. B. (1972), Characteristics of organizational environments and perceived environmental 
uncertainty, Administrative Science Quarterly, Vol. 17, pp. 313-27.

24. Elango, B., Paul, K., Kundu, S. K. and Paudel, S. K. (2010), Organizational ethics, individual ethics, and ethical intentions in international decision-making, Journal of Business Ethics, Vol. 97, pp. 543-561.

25. Elçi, M. and Alpkan, L. (2006), The impact of perceived organizational ethical climate on work satisfaction, Journal of Business Ethics, Vol. 84, No. 3, pp. 297-311.

26. Everett, J., Green, D. and Neu, D. (2005), Independence, objectivity and the Canadian CPA profession, Critical Perspectives in Accounting, Vol. 16, pp. 415-440.

27. Falkenberg, L. and Herremans, I. (1995), Ethical behaviors in organizations: Directed by the formal or informal system, Journal of Business Ethics, Vol. 14, pp. 133-143.

28. Ferrell, O. C., Gresham, L. G. and Fraedrich, J. (1989), A synthesis of ethical decision models for marketing, Journal of Macro-Marketing, Vol. 9, No. 2, pp. 55-64.

29. Fritzche, D. J. and Becker, H. (1984), Linking management behavior to ethical philosophy, Academy of Management Journal, Vol. 27, pp. 166-175.

30. Gaa, J. C. (1995), Moral judgment and moral cognition: A comment, in Ponemon, L. (Ed), Research on Accounting Ethics, Vol. 1, pp. 253-265, JAI Press, Greenwich.

31. Gaa, J. C. and Thorne, L. (2004), An introduction to the special issue on professionalism and ethics in accounting, Issues in Accounting Education, Vol. 19, No. 1, pp. 1-6.

32. Gerloff, E. A., Muir, N. K. and Bodensteiner, W.D. (1991), Three components of perceived environmental uncertainty: an exploratory analysis of the effects of aggregation, Journal of Management, Vol. 17, No. 4, pp. 749-768.

33. Goldman, A. and Tabak, N. (2010), Perception of ethical climate and its relationship to nurses' demographic characteristics and job satisfaction, Nursing Ethics, Vol. 17, No. 2, pp. 233-246.

34. Gordon, L. A. and Narayanan, V. K. (1984), Management accounting systems, perceived environmental and organization structure: An empirical investigation, Accounting, Organizations and Society, Vol. 9 , No.1, pp. 33-47.

35. Gouldner, A. W. (1957), Cosmopolitans and locals: Toward an analysis of latent social roles, Administrative Science Quarterly, Vol. 2, pp. 281-306.

36. Greer, L. and Tonge, A. (2006), Ethical foundations: A new framework for reliable financial reporting, Business Ethics: A European Review, Vol. 15, No. 3, pp. 259-270.

37. Gresov, C., Drazin, R. and Van de Ven, A. H. (1989), Work-unit task uncertainty, design and morale, Organization Studies, Vol. 10, No. 1, pp. 45-62.

38. Grojean, M. W., Resick, C. K., Dickson, M. W. and Smith, D. B. (2004), Leaders, values, and organizational climate: Examining leadership strategies for establishing an organizational climate regarding ethics, Journal of Business Ethics, Vol. 55, pp. 223-241.

39. Gul, F. (1991), The effects of management accounting systems and environmental uncertainty on small business managements' performance, Accounting and Business Research, Vol. 22, pp. 57-61.

40. Gul, F. and Chia, Y. M. (1994), The effects of management accounting systems, perceived environmental uncertainty and decentralization on managerial performance, Accounting, Organizations and Society, Vol. 19, No. 4/5, pp. 413-26.

41. Henman, L. D. (2013), A CFO's guide to corporate governance, Henman Performance Group, www.henmanperformancegroup.com

42. House, R. J. and Aditya, R. (1997), The social scientific study of leadership: Quo vadis?, Journal of Management, Vol. 23, pp. 409-474.

43. Hunt, S. D., Wood, V. R. and Chonko, L. B. (1989), Corporate ethical values and organizational commitment in marketing, Journal of Marketing, Vol. 53, July, pp. 79-90.

44. International Federation of Accountants and Chartered Institute of Management Accountants. (2004), Enterprise governance: Getting the balance right, New York.

45. International Federation of Accountants. (2003), Rebuilding public confidence in financial reporting: An international perspective, New York.

46. International Federation of Accountants. (2005), The roles and domain of the professional accountant in business, New York.

47. International Federation of Accountants. (2006a), Code of Ethics for Professional Accountants, New York. 48. International Federation of Accountants. (2006b), Defining and Developing an Effective Code of Conduct, New York. 
49. International Federation of Accountants. (2008), Financial reporting supply chain: Current perspectives and directions, New York.

50. International Federation of Accountants. (2009), International good practice guidance: evaluating and improving governance in organizations, New York.

51. Ireland, R. D. and Hitt, M. A. (1999), Achieving and maintaining strategic competitiveness in the $21^{\text {st }}$ century: The role of strategic leadership, Academy of Management Executive, Vol. 13, pp. 43-57.

52. Jackling, B., Cooper, B. J., Leung, P. and Dellaportas, S. (2007), Professional accounting bodies' perceptions of ethical issues, causes of ethical failure and ethics education, Managerial Auditing Journal, Vol. 22, No. 9, pp. 928-944.

53. Jackson, R. W., Wood, C. M. and Zboha, J. J. (2013), The dissolution of ethical decision-making in organizations: A comprehensive review and model, Journal of Business Ethics, Vol. 116, pp. 233-250.

54. Jaramillo, F., Mulki, J. P. and Solomon, P. (2006), The role of ethical climate on salesperson's role stress, job attitudes, turnover intention, and job performance, Journal of Personal Selling \& Sales Management, Vol. 26, pp. 271-282.

55. Jones, T. M., Felps, W. and Bigley, G. A. (2007), Ethical theory and stakeholder-related decisions: the role of stakeholder culture, Academy of Management Review, Vol. 32, No. 1, pp. 137-155.

56. Joseph, J. and Deshpande, S. P. (1997), The impact of ethical climate on job satisfaction of nurses, Health Care Management Review, Vol. 22, No. 1, pp. 76-81.

57. Kaptein, M. and Schwartz, M. S. (2008), The effectiveness of business codes: A critical examination of existing studies and the development of an integrated research model, Journal of Business Ethics, Vol. 77, No. 2, pp. 111-127.

58. Khandwalla, P. N. (1972), The effect of different types of competition on the use of management controls, Journal of Accounting Research, Vol. 10, pp.275-85.

59. Kohlberg, L. (1984), The psychology of moral development, Harper and Row Publishers, San Francisco.

60. Kren, L. (1992), Budgetary participation and managerial performance: The impact of information and environmental volatility, The Accounting Review, Vol. 67, pp. 511-526.

61. Lawrence, P. R. and Lorsch, J. W. (1967), Organization and Environment, Harvard University, Cambridge, MA.

62. Leung, P. and Cooper, B. J. (2005), Accountants, ethical issues and the corporate governance context, Australian Accounting Review, Vol. 15, pp. 79-88.

63. Loe, T. W., Ferrell, L. and Mansfield, P. (2000), A review of empirical studies assessing ethical decision making in business, Journal of Business Ethics, Vol. 25, pp. 185-204.

64. Loeb, S. E. (2007), Issues relating to teaching accounting ethics: An 18 year retrospective, in Jeffrey, C. (Ed.), Research on Professional Responsibility and Ethics on Accounting, Vol. 11, pp. 1-30, Elsevier, Oxford.

65. Mascarenhas, O. A. J. (1995), Exonerating unethical marketing executive behaviors: A diagnostic framework, Journal of Marketing, Vol. 59, pp. 43-57.

66. Merton, R. K. (1957), Social theory and social structure, The Free Press, New York.

67. Miles, R. E. and Snow, C. C. (1978), Organizational strategy, structure and process, McGraw-Hill, New York.

68. Milliken, F. J. (1987), Three types of perceived uncertainty about the environment: state, effect, and response uncertainty, Academy of Management Review, Vol. 27. No.1, pp. 133-143.

69. Minett, S. (2002), B2B marketing: A radically different approach for business-to-business marketers, Pearson Education Limited, London.

70. Monks, R. A. G. (2002), Creating value through corporate governance, Corporate Governance: An International Review, Vol. 10, No. 3, pp. 116-123.

71. Mulki, J. P., Jaramillo, F. and Locander W. B. (2006), Effects of ethical climate and supervisory trust on salesperson's job attitudes and intentions to quit, Journal of Personal Selling \& Sales Management, Vol. 26, pp. 19-26.

72. Murphy, P., Smith, J. and Daley J. 1992, Executive attitudes, organizational size and ethical issues: Perspectives on a service industry, Journal of Business Ethics, Vol.11, pp. 11-19.

73. Nunnally, J. C. (1967), Psychometric theory, McGraw Hill, New York.

74. Page, R. C. and Tornow, W. W. (1987), Managerial job analysis: Are we further along?, Paper presented at the annual conference of the Society for Industrial and Organizational Psychology, Atlanta, GA. 
75. Perrow, C. (1967), Organizational analysis: A sociological review, Wadsworth Publishing, Belmont, CA.

76. Perrow, C. (1970), Organizational analysis: A sociological review, Wadsworth Publishing, Belmont, CA.

77. Pimentel, J. R. C., Kuntz, J. R. and Elenkov, D. S. (2008), Ethical decision-making: An integrative model for business practice, European Business Review, Vol. 22, No. 4, pp. 359-376.

78. Ponemon, L. (1990), Ethical judgments in accounting: A cognitive-developmental perspective, Critical Perspectives on Accounting, Vol. 1, No. 2, pp. 191-215.

79. Ponemon, L. (1995), The objectivity of accountant litigation support judgments, The Accounting Review, Vol. 70, pp. 467-488.

80. Rajeev, P. N. (2012), Correlates of ethical intentions: A critical review of empirical literature and suggestions for future research, Journal of International Business Ethics, Vol. 5, No. 1, pp. 3-17.

81. Robertson, D. C. and Anderson, E. (1993), Control system and task environment effects of ethical judgment: An exploratory study of industrial salespeople, Organization Science, Vol. 4, No. 4, pp. 617644.

82. Satava, D., Caldwell, C. and Richards, L. (2006), Ethics and the auditing culture: Rethinking the foundation of accounting and auditing, Journal of Business Ethics, Vol. 64, pp. 271-284.

83. Schein, E. (1992), Organizational culture and leadership ( $2^{\text {nd }}$ Ed.), Jossey-Bass, San Francisco.

84. Schminke, M., Ambrose, M. L. and Neubaum, D. O. (2005), The effect of leader moral development on ethical climate and employee attitudes, Organizational Behavior and Human Decision Processes, Vol. 97, pp. 135-151.

85. Schneider, B. (1975), Organizational climates: An essay, Personal Psychology, Vol. 28, pp. 447-479.

86. Schwepker, C. H., Ferrell, O. C. and Ingram, T. N. (1997), The influence of ethical climate and ethical conflict on roles stress in the sales force, Journal of Marketing Science, Vol. 25, pp. 99-108.

87. Sennetti, J. T., Shawver, T. J. and Bancroft, P. C. (2004), The moral and cultural reasoning of IPO accountants: A small sample study, in Jeffrey, C. (Ed.) Research on professional responsibility and ethics in accounting, Vol. 9, pp. 101-128, Elsevier, Oxford.

88. Sharfman, M.P. and Dean, W. D. Jr. (1991), Conceptualizing and measuring the organizational environment: A multidimensional approach, Journal of Management, Vol. 17, No. 4, pp. 681-700.

89. Sharma, D. S. (2002), The differential effect of environmental dimensionality, size, and structure on budget system characteristics in hotels, Management Accounting Research, Vol. 13, pp. 101-130.

90. Shleifer, A. (2004), Does competition destroy ethical behavior?, American Economic Review, Vol. 94, pp. 414-418.

91. Simha, A. and Cullen, J. B. (2011), Ethical climates and their effects on organizational outcomes: Implications from the past and prophecies for the future, Academy of Management Perspectives, November, pp. 20-34.

92. Sinclair, A. (1993), Approaches to organizational culture and ethics, Journal of Business Ethics, Vol. 12, pp. 63-73.

93. Smidt, J. J.: 1998, Army leadership: doctrine and the new FM 22-100, Military Review, Vol. 78, pp. 83-86.

94. Stewart, R., Volpone, S. D., Avery, D. R. and McKay, P. (2011), You Support Diversity, But Are You Ethical? Examining the interactive effects of diversity and ethical climate perceptions on turnover intentions, Journal of Business Ethics, Vol. 100, pp. 581-593.

95. Trevino, L. (1986), Ethical decision making in organizations: A person-situation interactionist model, Academy of Management Review, Vol. 11, No. 3, pp. 601-617.

96. Tsai, M.T. and Huang, C. C. (2008), The relationship among ethical climate types, facets of job satisfaction, and the three components of organizational commitment: A study of nurses in Taiwan, Journal of Business Ethics, Vol. 80, pp. 565-581.

97. Tushman, M. L. and Nadler, D. A. (1978), Information processing as an integrating concept in organizational design, Academy of Management Review, Vol. 3, pp. 613-24.

98. Tymon, W. G. Jr., Stout, D. E. and Shaw, K. N. (1998), Critical analysis and recommendations regarding the role of perceived environmental uncertainty in behavioral accounting research, Behavioral Research in Accounting, Vol. 10, pp. 23-46.

99. Uysal, Ö. Ö. (2010), Business ethics research with an accounting focus: A bibliometric analysis from 1988 to 2007, Journal of Business Ethics, Vol. 93, pp. 137-160.

100. Victor, B. and Cullen, J. B. (1987), A theory and measure of ethical climate in organizations, Research in Corporate Social Performance and Policy, Vol. 9, pp. 51-71. 
101. Victor, B. and Cullen, J. B. (1988), The organizational basis of ethical work climates, Administrative Science Quarterly, Vol. 33, pp. 95-119.

102. Waddock, S. (2005), Hollow men and women at the helm... hollow accounting ethics?, Issues in Accounting Education, Vol. 20, No. 2, pp. 145-150.

103. Wang, Y. D. and Hsieh, H. H. (2012), Toward a better understanding of the link between ethical climate and job satisfaction: A multilevel analysis, Journal of Business Ethics, Vol. 105, pp. 535-545.

104. Weeks, W. A., Loe, T. W, Chonko, L.B. and Wakefield, K. (2004), The effect of perceived ethical climate on the search for sales force excellence, Journal of Personal Selling and Sales Management, pp. 199 - 214.

105. Williams, B. (1985), Ethics and the limits of philosophy, Harvard University Press, Cambridge, MA.

106. Williams, J. J. and Seaman, A. E. (2010), Corporate governance and mindfulness: The impact of management accounting systems change, The Journal of Applied Business Research, Vol. 26, No. 5, pp, 117.

107. Williams, P. F. (2002), Accounting and the moral order: Justice, accounting, and legitimate moral authority, Critical Perspectives on Accounting, Vol. 2, pp. 1-21.

108. Wimbush, J., Shepard, J. and Markham, S. (1997), An empirical examination of the relationship between ethical climate and ethical behavior from multiple levels of analysis, Journal of Business Ethics, Vol. 16, pp. 1705-1717.

109. Young, J. J. and Annisette, M. (2009), Cultivating Imagination: ethics, education and literature, Critical Perspectives in Accounting, Vol. 20, No. 1, pp. 93-109.

110. Zaccaro, S. J. (1996), Models and theories of leadership, U.S. Army Research Institute for the Behavioral and Social Sciences, Alexandria, VA. 


\section{NOTES}

